\title{
Chest and occipito-frontal circumference measurements in the detection of low birth weight among Nigerian newborns of Igbo ethnicity
}

\author{
Ikenna K Ndu*, Stella N Ibeziako², Egbuna O Obidike², Gilbert N Adimora², Benedict O Edelu², \\ Josephat M Chinawa ${ }^{2}$, Isaac N Asinobi ${ }^{2}$ and Nwachinemere D Uleanya ${ }^{1}$
}

\begin{abstract}
Background: The World Health Organisation has recommended the use of anthropometric measurements as birth weight surrogates. However, it has been found that cut-off points for these anthropometric measurements vary across nations and ethnic groups.
\end{abstract}

Objectives: To determine the predictive values of chest circumference (CC), occipito-frontal circumference (OFC) and their combinations for low birth weight (LBW) detection in lgbo newborns.

Methods: Live newborns of Igbo origin were recruited within 24 hours of delivery. Their CC, OFC and weight were measured. Cut off points for predicting low birth weight was determined using ROC analysis.

Results: A total of 511 live newborns were recruited. For birth weight $<2500$ g, cut-off values were: CC $30.9 \mathrm{~cm}$; OFC $33.8 \mathrm{~cm}$; summation of CC and OFC $64.9 \mathrm{~cm}$; ratio of CC to OFC 0.92. For weight $<2000 \mathrm{~g}$, the cut-off values were: CC $29.6 \mathrm{~cm}$; OFC $32.8 \mathrm{~cm}$; summation of CC and OFC $63.7 \mathrm{~cm}$; ratio of CC to OFC 0.91. CC correlated best with birth weight $(r=0.918)$.

Conclusion: CC is the best predictor for LBW.

Keywords: Predictive values, Chest circumference, Occipito-frontal circumference, Nigeria, Birth weight

\section{Introduction}

Birth weight is a critical determinant of survival, growth and development of the newborn and also a valuable indicator of maternal health, nutrition and quality of antenatal services [1]. Newborns weighing less than 2500 grams are described as low birth weight (LBW) and have a greater risk of morbidity and mortality [2]. Thus birth weight measurement is an important screening tool for detecting the newborn at risk with special reference to low birth weight.

More than 20 million newborns worldwide are LBW and it is the single most important underlying risk factor for neonatal deaths $[3,4]$. It is estimated that $90 \%$ of this global burden occurs in developing countries [5] where on the average, $58 \%$ of newborn infants are not weighed at birth [3]. The reasons adduced for this are absence of

\footnotetext{
* Correspondence: ikennandu@gmail.com

${ }^{1}$ Enugu state University Teaching Hospital, Park lane, Enugu, Nigeria

Full list of author information is available at the end of the article
}

trained personnel, or that weighing scales may nonfunctional or unavailable at places of delivery [6-9].

This challenge notwithstanding, hospital based studies in Nigeria have shown that LBW is responsible for 63\% of infant mortality as well as $45.2 \%$ of perinatal deaths and carries a 37-fold increased risk of death in the first year of life [10-12]. These findings agree with a World Health Organization (WHO) estimate that almost half of newborn mortality is associated with preterm or low birth weight babies [13].

An additional advantage of early identification of LBW babies especially in resource-poor settings is to enable prompt referral which may determine survival [14]. For practical purposes some authors recommend $2000 \mathrm{~g}$ as the basis for hospitalizing LBW babies $[7,15]$. To improve detection of LBW especially in resource-poor countries, alternative measurements have been studied in different racial groups and include chest circumference (CC) $[6,15,16]^{\prime}$ occipito-frontal circumference (OFC) $[17,18]$, 
mid arm circumference (MAC) $[6,19]$ and maximum thigh circumference (MTC). CC is preferred because the landmark is easily identified and has less chance of measurement errors $[6,20]$. The combination of OFC and CC has also been found to be a good predictor for estimation of birth weight in view of the simplicity and non-invasiveness of measuring these two body circumferences [21].

This study was designed to correlate birth weight with $\mathrm{CC}$ and OFC and their combinations as summation and ratio. Their suitability in detecting potential LBW newborn babies in a predominantly Igbo ethnic group domain was determined.

\section{Subjects and methods}

This was a hospital based, cross-sectional and descriptive multi centre study carried out in two tertiary (University of Nigeria Teaching Hospital (UNTH), Enugu, Enugu State University Teaching Hospital (ESUTH), Enugu) and one secondary health facility (Mother of Christ Specialist Hospital (MCSH), Enugu). They are all equipped with infrastructures to cater to different aspects of medicine, including Obstetrics and Paediatric practice for the state and its environs. The study was carried out between $1^{\text {st }}$ September and $31^{\text {st }}$ December 2011, at the three study centres.

Inclusion criteria include live newborns delivered at the study centers, irrespective of gestational age, sex or mode of delivery and whose parents are of Igbo tribe. Babies with gross congenital abnormalities and those whose parents refused consent were excluded in the study.

Ethical approval was obtained from the Research and Ethics Committee of the three hospitals before commencement. Informed consent was obtained from the parent/guardian of each subject before recruitment. All newborn babies who met the study criteria were recruited within the first 24 hours of delivery. The data collected included CC, OFC and weight measurements.

\section{Body measurements (CC, OFC and weight)}

To ensure reliability and avoid inter-observer bias, all measurements were taken by one researcher alone. In addition, the anthropometric measurements were recorded before recording the birth weight to minimise potential intra-observer bias. The measurements were taken within the first 24 hours of delivery because of postnatal changes in body water composition and balance [22,23]. A particular sequence of taking measurements was adhered to: OFC first, followed by CC then weight. This was to minimise exposure time and reduce risk of hypothermia. All measurements were taken with the subject lying down.

Chest circumference was measured at the level of the nipple, at the end of expiration, to the nearest $0.1 \mathrm{~cm}$ using a non-elastic, flexible, fibre glass measuring tape according to standard techniques described by Forfar [24].
Occipito-frontal circumference was measured as the maximum circumference of the head to the nearest 0.1 $\mathrm{cm}$ with a non-elastic, flexible, fibre glass measuring tape passing above the supra-orbital ridges and over the maximum occipital prominence.

All the newborns were weighed naked on a Waymaster infant spring weighing scale to the nearest 50 grams.

Gestational age assessment was corroborated by physical assessment using the New Ballard Score [25]. Where there was discordance between the gestational age by date and the New Ballard Score, the later was used. Social classification was done using the socioeconomic index scores designed by Oyedeji [26].

\section{Data analysis}

All the data obtained was recorded and analyzed using the Statistical Package for Social Sciences (SPSS) version 19.0 and SYSTAT version 13. Continuous variables (CC, $\mathrm{OFC})$ were reported as mean and standard deviation while categorical variables were reported as the number or percentage of subjects with a particular characteristic. The combination of CC and OFC as summation and ratio were also analysed. Chi square was used to test for association between Weight categories and Sex distribution of the newborns. Continuous variables were compared using student's t test and one-way ANOVA while prediction of birth weight by anthropometric variables was done using linear regression analysis. A p-value less than 0.05 was accepted as significant. Receiver operating characteristic curve analysis was used to identify the cut-off values for the different anthropometric measurements to predict LBW. The sensitivity, specificity and predictive values were calculated at serial cut-off points while the area under the curve was determined to evaluate the overall accuracy. Results were presented as prose, tables and figures as appropriate.

\section{Results}

\section{Characteristics of study population}

A total of 511 newborns who met the inclusion criteria, out of 857 newborn deliveries in the three centres within the study period. One hundred and eighty three babies (35.8\%) were recruited from ESUTH, while 178 (34.8\%) and 150 (29.4\%) were recruited from MCSH and UNTH respectively.

There were 267 males and 244 females giving a sex ratio of 1.1:1. Fourteen percent were of LBW, $82.6 \%$ were normal birth weight while $3.3 \%$ were macrosomic. There was no significant gender difference in the weight categories $\left(X^{2}=2.984, p=0.225\right)$, see Table 1 . Forty nine $(9.6 \%)$ of the births were preterm, $448(87.7 \%)$ were term, while $14(2.7 \%)$ were post term. The birth weights (BW) of the subjects ranged from $650 \mathrm{~g}$ to $4500 \mathrm{~g}$, with a mean $\mathrm{BW}$ of $3110.50 \pm 617.51 \mathrm{~g}$. The mean $\mathrm{BW}$ of the 
Table 1 Weight categories and sex distribution of the newborns

\begin{tabular}{llll}
\hline Weight & Males & Females & Total \\
& Frequency (\%) & Frequency (\%) & Frequency (\%) \\
\hline$<2500 \mathrm{~g}$ & $31(11.6)$ & $41(16.8)$ & $72(14.1)$ \\
$2500-3999 \mathrm{~g}$ & $226(84.6)$ & $196(80.3)$ & $422(82.6)$ \\
$\geq 4000 \mathrm{~g}$ & $10(3.8)$ & $7(2.9)$ & $17(3.3)$ \\
Total & $267(100)$ & $244(100)$ & $511(100)$ \\
\hline
\end{tabular}

$x^{2}=2.984, p=0.225$.

males $(3205.61 \pm 614.60 \mathrm{~g})$ was higher than that of the female babies $(3006.07 \pm 604.13 \mathrm{~g}), \mathrm{t}=3.678, \mathrm{p}=0.000$.

Anthropometric parameters for different weight categories The total mean $\mathrm{CC}$ was $33 \pm 2.8 \mathrm{~cm}$ while the total mean $\mathrm{OFC}$ was $34.7 \pm 2.0$. CC/OFC (ratio) and $\mathrm{CC}+\mathrm{OFC}$ (summation) had total means of $0.94 \pm 0.05$ and $67.8 \pm$ 4.6 respectively. Analysis of variance showed statistically significant difference among the three weight categories with respect to the measurements Table 2 .

\section{Linear regression analysis}

Four linear regression models were created, one each for $\mathrm{CC}, \mathrm{OFC}, \mathrm{CC}+\mathrm{OFC}$ (sum) and CC/OFC (ratio) as independent variables and birth weight as dependent variable. The highest coefficient of correlation (R) and coefficient of determination $\left(\mathrm{R}^{2}\right)$ were associated with $C \mathrm{C}$ followed by the sum of the circumferences, OFC and ratio of circumferences in that order. All the correlations were significant at $\mathrm{p}<0.001$. Also, the lowest standard error of the estimate (SEE) was observed with $\mathrm{CC}$, followed by $\mathrm{CC}+\mathrm{OFC}$, $\mathrm{OFC}$ and $\mathrm{CC} / \mathrm{OFC}$ ratio in that order. $\mathrm{CC}$ had a higher coefficient of determination $\left(\mathrm{R}^{2}\right)$ when compared with OFC. Summation of these two variables (CC and OFC) had a higher coefficient of determination $\left(R^{2}\right)$ than OFC, however the $\mathrm{R}^{2}$ was lower than that of $\mathrm{CC}$. The ratio of the parameters gave a coefficient of determination $\left(R^{2}\right)$ less than 0.5. The multiple regression model using $\mathrm{CC}$ and OFC as independent co-variables produced a higher coefficient of

Table 2 Mean values of anthropometric variables for the different weight categories

\begin{tabular}{llllll}
\hline Birth weight group $(\mathbf{g})$ & & & & \\
\hline Parameter & $<\mathbf{2 5 0 0}$ & $\mathbf{2 5 0 0 - 3 9 9 9}$ & $\mathbf{2} \mathbf{4 0 0 0}$ & F-value & p-value \\
& $\mathbf{n}=\mathbf{7 2}$ & $\mathbf{n}=\mathbf{4 2 2}$ & $\mathbf{n}=\mathbf{1 7}$ & & \\
& Mean \pm SD & Mean \pm SD & Mean \pm SD & & \\
\hline CC (cm) & $28.10 \pm 2.51$ & $33.70 \pm 1.73$ & $38.50 \pm 1.41$ & 360.0 & $<0.01$ \\
OFC (cm) & $31.50 \pm 2.62$ & $35.30 \pm 1.30$ & $36.65 \pm 1.06$ & 190.1 & $<0.01$ \\
CC + OFC (cm) & $59.60 \pm 4.94$ & $68.94 \pm 2.69$ & $75.12 \pm 2.14$ & 329.1 & $<0.01$ \\
CC/OFC & $0.89 \pm 0.04$ & $0.96 \pm 0.04$ & $1.05 \pm 0.03$ & 134.2 & $<0.01$ \\
ratio & & & & & \\
\hline
\end{tabular}

$\mathrm{CC}=$ chest circumference, $\mathrm{OFC}=$ Occipito-frontal circumference. determination $\left(\mathrm{R}^{2}\right)$ and lower standard error of the estimate (SEE) than any of the other four simple linear regression models (Table 3).

Four scatter plot graphs were created, each representing $\mathrm{CC}, \mathrm{OFC}, \mathrm{CC}+\mathrm{OFC}$ (sum), CC/OFC (ratio) for newborns weighing less than $2500 \mathrm{~g}$ (Figures 1a-d). There was a linear relationship between the anthropometric measurements and birth weight as shown by the positive gradients of the scatter plot diagrams. The highest coefficient of determination $\left(\mathrm{R}^{2}\right)$ was associated with $\mathrm{CC}$ followed by the sum of the circumferences, OFC and ratio of circumferences in that order.

Four scatter plot graphs were created, each representing $\mathrm{CC}$, OFC, CC + OFC (sum), CC/OFC (ratio) for newborns weighing less than $2000 \mathrm{~g}$ (Figures 2a-d). There was a linear relationship between the anthropometric measurements and birth weight as shown by the positive gradients of the scatter plot diagrams. The highest coefficient of determination $\left(\mathrm{R}^{2}\right)$ was associated with $\mathrm{CC}$ followed by the sum of the circumferences, OFC and ratio of circumferences in that order.

\section{ROC curve analysis for cut-off point determination}

Table 4 shows that both CC and summation of CC and OFC had the best discrimination for birth weight less than $2500 \mathrm{~g}$. Although the AUCs for CC and summation were equal, their shapes were not identical (Figures 3a and c). In this situation, the test with the higher accuracy at the optimum cut-off points has the better discrimination. Comparing CC and CC + OFC (summation) specifically at their optimal cut-off points, CC has a higher accuracy of $94 \%$ as against $93 \%$ for summation. CC and the summation of CC and OFC gave the best discrimination for birth weight less than $2000 \mathrm{~g}$. They both had equal AUCs and the same accuracy of $92 \%$.

The corresponding ROC curves for CC, OFC, CC+ OFC and CC/OFC ratio as surrogates for birth weight less than $2500 \mathrm{~g}$ are shown in Figures 3a to 3d. For CC, the identified cut-off point was $30.9 \mathrm{~cm}$ with a sensitivity of $91.4 \%$ and $\{1-$ specificity $\}$ of $5.3 \%$. The optimal cutoff point for OFC was $33.8 \mathrm{~cm}$ with a sensitivity of $84.4 \%$ and $\{1-$ specificity $\}$ of $10.1 \%$. With respect to sum of circumferences, the optimal cut-off was $64.9 \mathrm{~cm}$ with a sensitivity of $92.2 \%$ and $\{1-$ specificity $\}$ of $6.5 \%$. Also, CC/OFC ratio had an optimal cut-off point of 0.92 with a sensitivity of $87.0 \%$ and $\{1-$ specificity $\}$ of $8.5 \%$ (Table 5).

The corresponding ROC curves for $\mathrm{CC}, \mathrm{OFC}, \mathrm{CC}+$ OFC and CC/OFC ratio as surrogates for birth weight less than $2000 \mathrm{~g}$ are shown in Figures 4a to 4d. For CC, the identified cut-off point was $29.6 \mathrm{~cm}$ with a sensitivity of $91.7 \%$ and $\{1-$ specificity $\}$ of $8.0 \%$. The optimal cutoff point for OFC was $32.8 \mathrm{~cm}$ with a sensitivity of $91.7 \%$ and $\{1-$ specificity $\}$ of $5.9 \%$. With respect to sum 
Table 3 Comparison of four simple linear regression models and a multiple regression model

\begin{tabular}{|c|c|c|c|c|c|c|}
\hline Variable & Regression equation & $\mathbf{R}$ & $\mathrm{R}^{2}$ & SEE & $\mathrm{t}$-value & $\mathrm{p}$-value \\
\hline $\mathrm{CC}$ & $W=190 C C-3204$ & 0.916 & 0.839 & 262.12 & 51.6 & $<0.01$ \\
\hline OFC & $W=232 \mathrm{OFC}-4999$ & 0.821 & 0.674 & 373.60 & 32.4 & $<0.01$ \\
\hline Summation & $W=113 S U M-4619$ & 0.912 & 0.832 & 268.24 & 50.2 & $<0.01$ \\
\hline Ratio & $W=8231$ Ratio -4720 & 0.647 & 0.418 & 498.99 & 19.1 & $<0.01$ \\
\hline $\mathrm{CC}, \mathrm{OFC}$ & $W=154 C C+530 F C-3815$ & 0.922 & 0.850 & 253.58 & 24.4 & $<0.01$ \\
\hline
\end{tabular}

$\mathrm{CC}=$ chest circumference, $\mathrm{OFC}=$ Occipito-frontal circumference.

of circumferences, the optimal cut-off was $63.7 \mathrm{~cm}$ with a sensitivity of $91.7 \%$ and $\{1-$ specificity $\}$ of $8.2 \%$. Also, $\mathrm{CC} / \mathrm{OFC}$ ratio had an optimal cut-off point of 0.91 with a sensitivity of $75.0 \%$ and $\{1-$ specificity $\}$ of $10.5 \%$ (Table 6).

\section{Discussion}

Birth weight is an important screening tool for detecting the newborn at risk with special reference to LBW [1]. The LBW incidence of $14 \%$ in the current study is comparable to the estimated national average of $12 \%$ [27]. Detecting LBW is a challenge in developing countries because of unavailable or unreliable weighing scales and deliveries outside healthcare facilities [3,6,7]. This has led to the need for alternative measurements to assess newborns.

In this current study involving babies of Igbo ethnic extraction form Nigeria, birth weight correlated very strongly with the anthropometric variables of $\mathrm{CC}, \mathrm{CC}+$ OFC (sum) and strongly with OFC. CC demonstrated
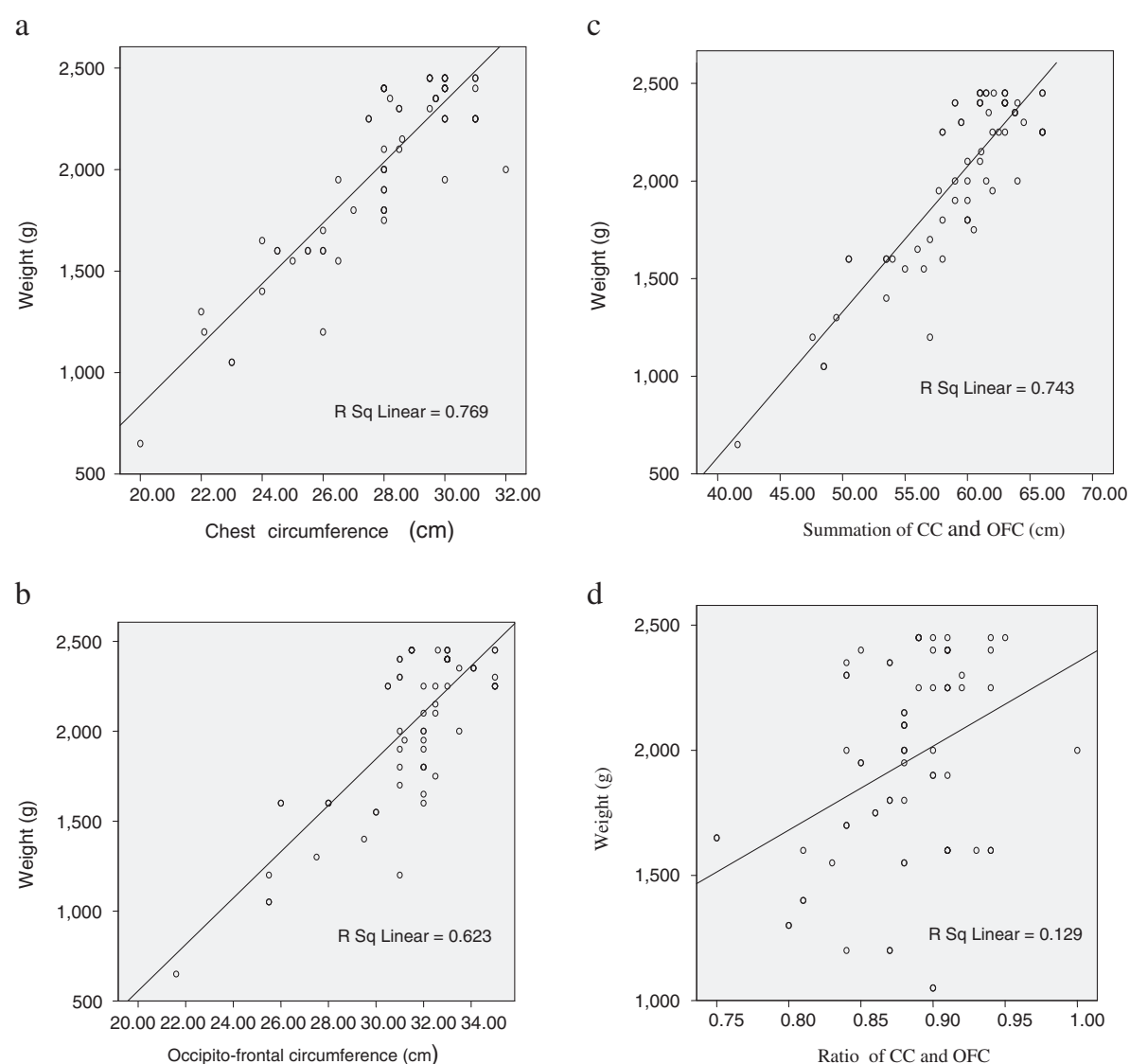

Figure 1 Scatter plots/regression lines of the different anthropometric parameters for birth weight <2500g. a: Scatter plot/regression line of birth weight $(\mathrm{g})$ on chest circumference $(\mathrm{cm})$ for newborns $<2500 \mathrm{~g}$. b: Scatter plot/regression line of birth weight (g) on occipitofrontal circumference for newborns $<2500 \mathrm{~g}$. c: Scatter plot/regression line of birth weight (g) on chest circumference + occipitofronal circumference $(\mathrm{cm})$ for newborns $<2500 \mathrm{~g}$. d: Scatter plot/regression line of birth weight $(\mathrm{g})$ on chest circumference (cc)/occipitofronal circumference (OFC) (ratio) for newborns $<2500 \mathrm{~g}$. 

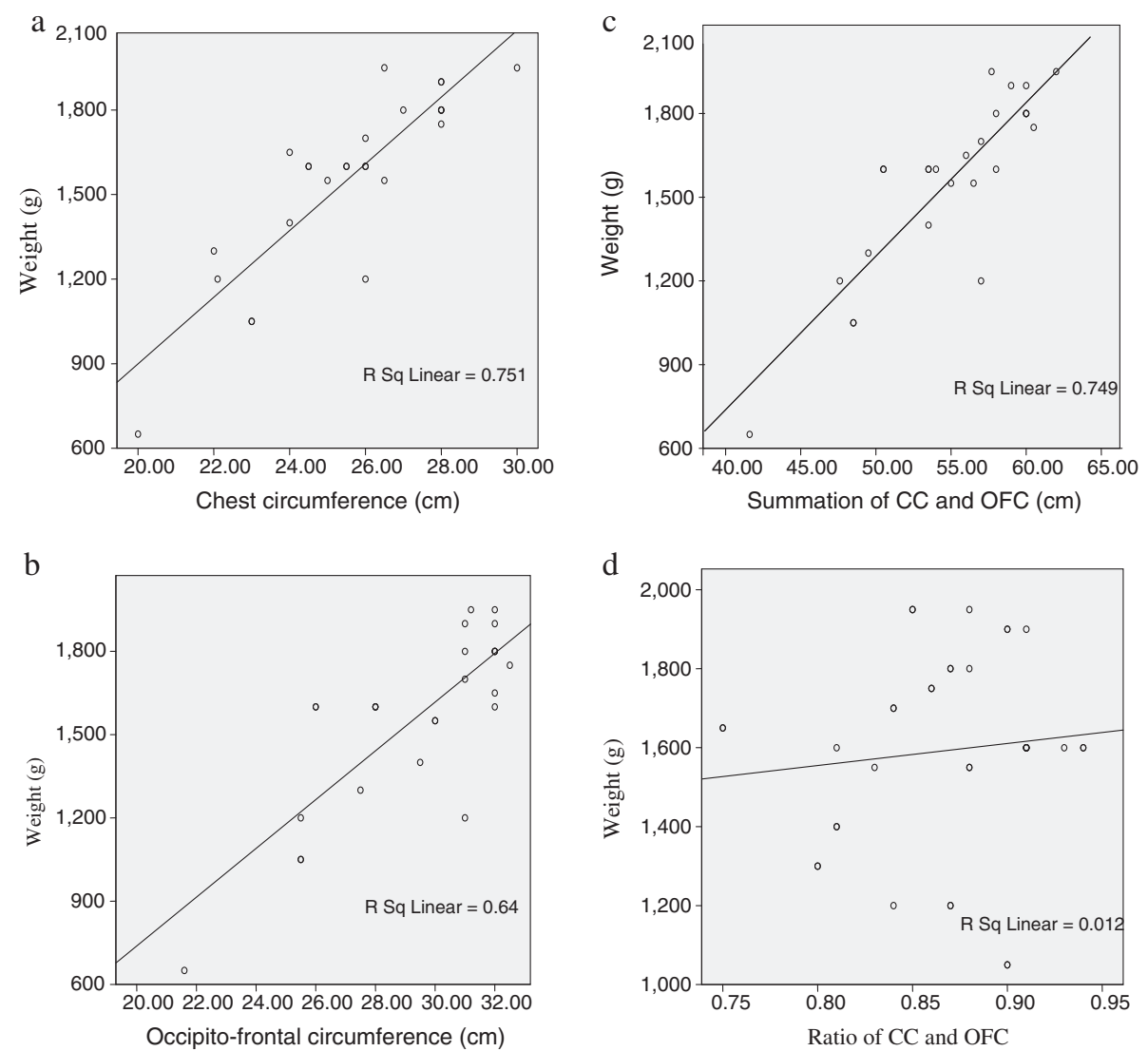

Figure $\mathbf{2}$ Scatter plots/ regression lines of the different anthropometric parameters for birth weight $<\mathbf{2 0 0 0}$ g. a: Scatter plot/regression line of birth weight $(\mathrm{g})$ on chest circumference $(\mathrm{cm})$ for newborns <2000 g. b: Scatter plot/regression line of birth weight (g) on occipitofronal circumference $(\mathrm{cm})$ for newborns $<2000 \mathrm{~g}$. c: Scatter plot/regression line of birth weight (g) on chest circumference + occipitofronal circumference (cm) for newborns <2000 g. d: Scatter plot/regression line of birth weight (g) on chest circumference (CC)/occipitofronal circumference (OFC) (ratio) for newborns $<2000 \mathrm{~g}$.

the best correlation with birth weight. This is similar to findings by Fawcus in Zimbabwe [28] respectively. It is also in keeping with findings from studies done in Asian countries which have reported good correlation between $\mathrm{CC}$ and birth weight ranging from 0.790 to 0.842 $[19,20,29]$. The high coefficient of correlation in the current study and the other studies cited above further reinforces the recommendation of the WHO collaborative

Table 4 ROC - AUC analysis for discrimination of birth weights below $2500 \mathrm{~g}$ and $2000 \mathrm{~g}$

\begin{tabular}{llllll}
\hline Birth weight & \multicolumn{2}{l}{$<\mathbf{2 5 0 0} \mathbf{g}(\mathbf{n}=\mathbf{7 2})$} & & \multicolumn{2}{c}{$\mathbf{2 0 0 0} \mathbf{g}(\mathbf{n}=\mathbf{2 6})$} \\
\cline { 2 - 3 } Parameter & AUC & $\mathbf{9 5 \%} \mathbf{~ C l}$ & & AUC & $\mathbf{9 5 \% ~ C l}$ \\
\hline CC $(\mathrm{cm})$ & 0.98 & $0.966-0.989$ & & 0.98 & $0.969-0.994$ \\
OFC $(\mathrm{cm})$ & 0.93 & $0.879-0.960$ & & 0.97 & $0.948-0.993$ \\
CC + OFC $(\mathrm{cm})$ & 0.98 & $0.968-0.991$ & & 0.98 & $0.973-0.997$ \\
CC/OFC & 0.93 & $0.899-0.963$ & & 0.93 & $0.897-0.967$ \\
\hline
\end{tabular}

$\mathrm{CC}=$ chest circumference, $\mathrm{OFC}=$ Occipito-frontal circumference. study [6] to use CC as an alternative measurement for detection of low birth weight. This strong correlation between CC and birth weight may be due to the fact that there are no significant soft tissue changes occasioned by the delivery process for $\mathrm{CC}$.

OFC correlated well with birth weight, though not as strong as that of CC. Variations in the degree of moulding and oedema may be responsible for the lower correlation when compared with CC. These soft tissue changes differ from baby to baby depending on the circumstances of labour such as prolonged and obstructed labour [17]. Such variation may likely affect the correlation between OFC and birth weight.

The summation of OFC and CC had a strong correlation with birth weight, superior to OFC alone and approaching that of CC. However, the summation of OFC and $\mathrm{CC}$ as a surrogate to birth weight requires mathematical calculation and thus may offer no practical advantage over CC alone. No previous study on summation of OFC and CC for prediction of birth weight was found. 

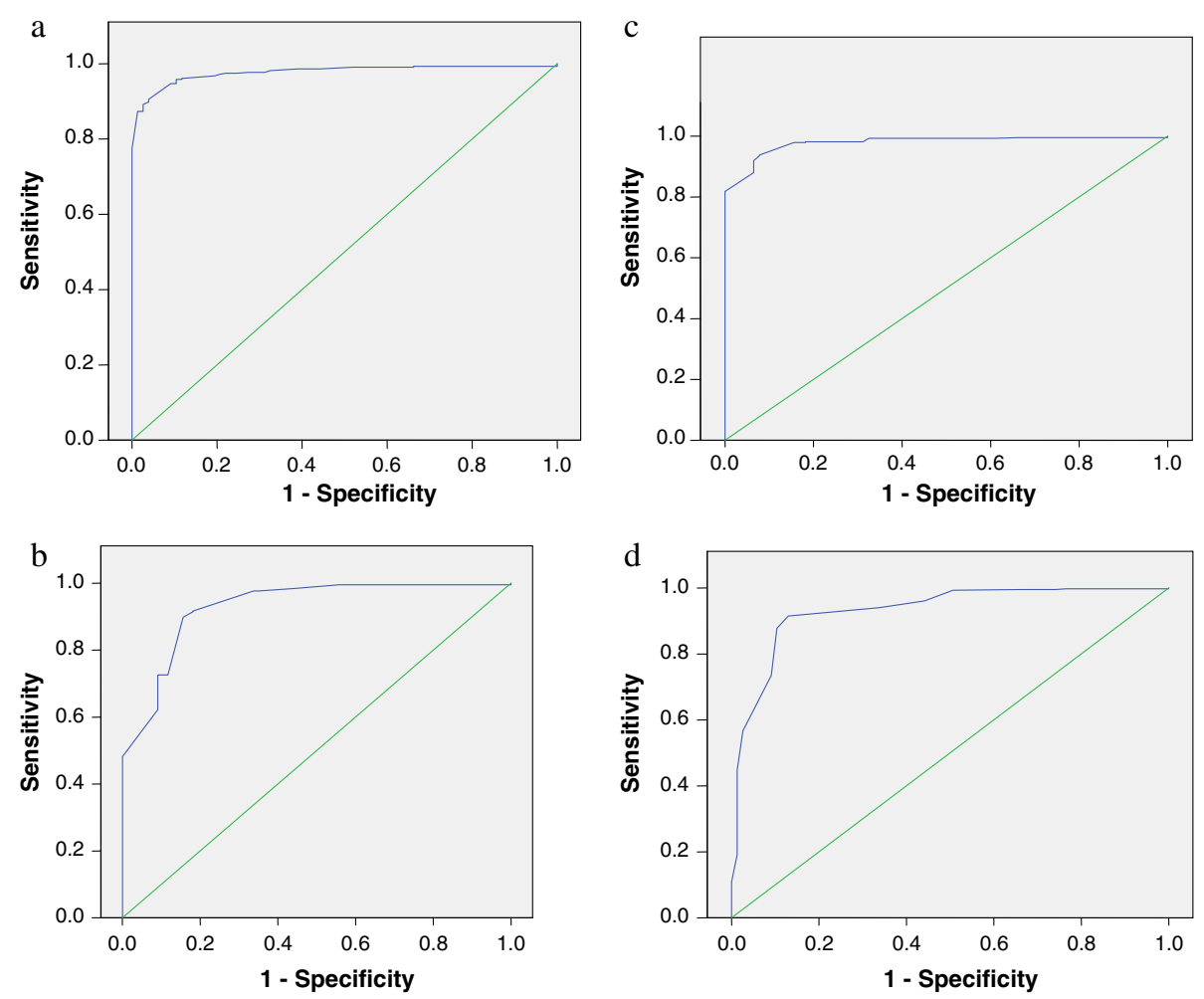

Figure $\mathbf{3}$ ROC Curves of the different anthropometric parameters for birth weight $<\mathbf{2 5 0 0} \mathbf{g}$. a: ROC curve for chest circumference as a surrogate for birth weight less than $2500 \mathrm{~g}$. b: ROC curve for occipito-frontal circumference as a surrogate for birth weight less than $2500 \mathrm{~g}$. c: ROC curve for chest circumference + occipitofrontal circumference as a surrogate for birth weight less than $2500 \mathrm{~g}$. d: ROC curve for CC/OFC (ratio) as a surrogate for birth weight less than $2500 \mathrm{~g}$.

CC/OFC ratio had the least correlation among all the parameters analysed in the current study. Furthermore, the ratio of the parameters gave a coefficient of determination $\left(R^{2}\right)$ less than 0.5 which indicates that less than half of the variation in birth weight can be explained by $\mathrm{CC} / \mathrm{OFC}$ ratio. Hence, there is no advantage in working out the ratio. It also requires calculation and may not be of much use to the semi-skilled labour attendant. No previous study was found on $\mathrm{CC} / \mathrm{OFC}$ ratio for prediction of birth weight.

The multiple regression model using $\mathrm{CC}$ and $\mathrm{OFC}$ as independent co-variables explains more variations that

Table 5 Predictive performance of selected median cut-off points of $\mathrm{CC}$, OFC, summation and ratio as surrogate indices for birth weight $<2500 \mathrm{~g}$

\begin{tabular}{lllll}
\hline Cut-off point $(\mathbf{c m})$ & Sensitivity & Specificity & PPV & NPV \\
\hline $30.9[C C]$ & 0.914 & 0.947 & 0.742 & 0.986 \\
$33.8[\mathrm{OFC}]$ & 0.844 & 0.899 & 0.581 & 0.973 \\
$64.9[C C+$ OFC] & 0.922 & 0.935 & 0.702 & 0.986 \\
$0.92[C C / O F C]$ & 0.870 & 0.915 & 0.630 & 0.978 \\
\hline
\end{tabular}

$\mathrm{PPV}=$ positive predictive, $\mathrm{NPV}=$ negative predictive value. exists in birth weight than any of the other four models and is thus the most predictive formula for birth weight calculation. However, it may have limited application in the field because of the calculations involved.

A previous study in Nigeria revealed that Igbo babies have the highest birth weights of other ethnic groups in Nigeria [30]. When compared to figures from outside Nigeria, the cut-off point for LBW in the current study was higher than values obtained by Fawcus [28] in Zimbabwe who reported $30 \mathrm{~cm}$. However it is similar to the value obtained by Moshen [17] in Egypt who reported a cut off point of $31 \mathrm{~cm}$ and those from Asia $[20,31]$. The findings of the current study and other studies from both Africa $[17,28]$ and Asia $[20,31]$ fall between a range of $29.0 \mathrm{~cm}$ and $31.0 \mathrm{~cm}$. This range may be considered wide enough to highlight the challenge in adopting a universal cut off for LBW.

The mean birth weight obtained in the current study is somewhat higher than that of Ezeaka et al. [18] in Lagos and Swende [32] in Makurdi who reported lower values of $2890 \mathrm{~g}$ and $3080 \mathrm{~g}$ respectively. It is however lower than the $3200 \mathrm{~g}$ obtained by Patwari and colleagues [30] who studied only babies from privileged 

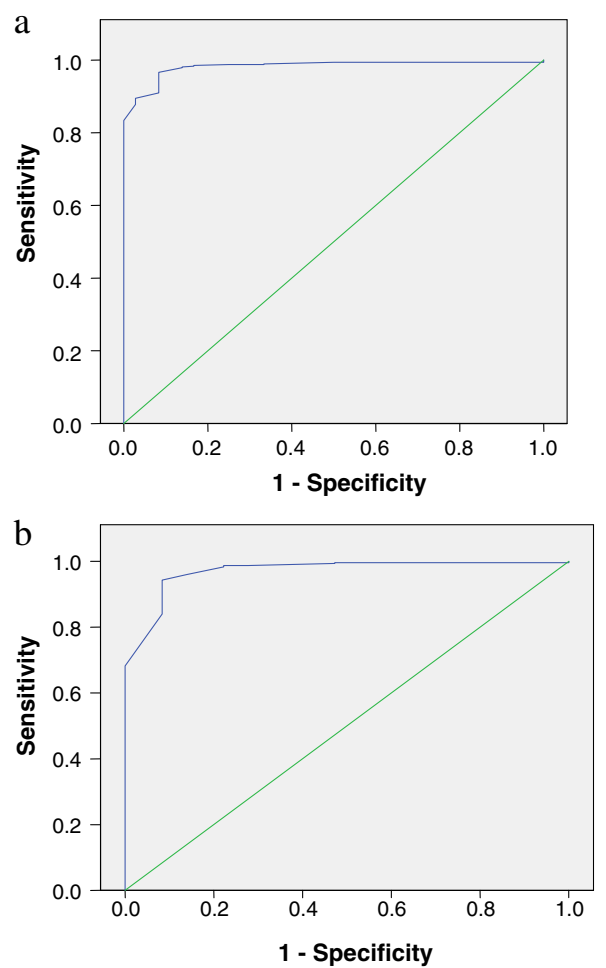

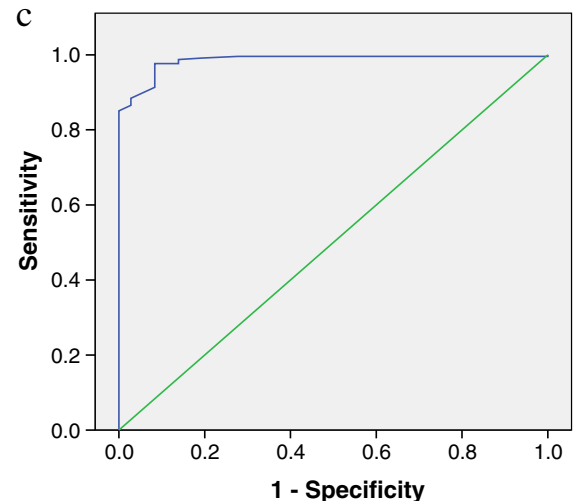

d

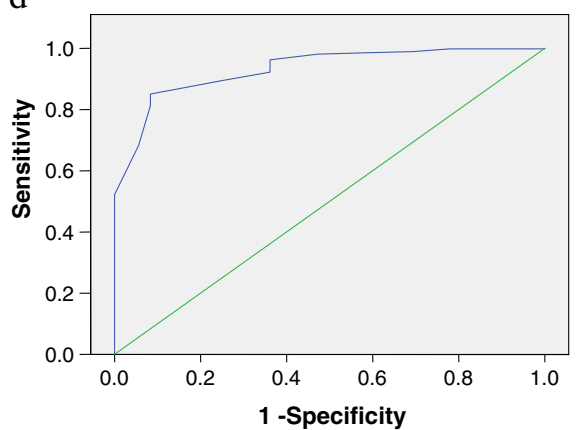

Figure $\mathbf{4}$ ROC Curves of the different anthropometric parameters for birth weight $<\mathbf{2 0 0 0} \mathbf{~ g . ~ a : ~ R O C ~ c u r v e ~ f o r ~ c h e s t ~ c i r c u m f e r e n c e ~ a s ~ a ~}$ surrogate for birth weight less than $2000 \mathrm{~g}$. b: ROC curve for occipitofrontal circumference as a surrogate for birth weight less than $2000 \mathrm{~g}$. c: ROC curve for chest circumference + occipitofrontal circumference as a surrogate for birth weight less than $2000 \mathrm{~g}$. d: ROC curve for chest circumference/occipitofronal circumference (ratio) as a surrogate for birth weight less than $2000 \mathrm{~g}$.

backgrounds in Maiduguri, a region with comparatively lower mean birth weight.

When compared to figures reported from outside Nigeria, the mean birth weight found in the current study is substantially higher than $2364 \mathrm{~g}$ and $2866 \mathrm{~g}$ observed in India and Vietnam respectively [6]. On the other hand, it is smaller than $3300 \mathrm{~g}$ to $3650 \mathrm{~g}$ from North America and Europe [33,34]. The reason for the observed differences could range from racial and ethnic to socioeconomic factors.

Development of colour coded tapes for use by midwives and TBAs or family members will facilitate identification and referral of LBW newborns. Based on the

Table 6 Predictive performance of selected median cut-off points of $\mathrm{CC}, \mathrm{OFC}$, summation and ratio as surrogate indices for birth weight $<2000 \mathrm{~g}$

\begin{tabular}{lllll}
\hline Cut-off point $(\mathbf{c m})$ & Sensitivity & Specificity & PPV & NPV \\
\hline $29.6(C C)$ & 0.917 & 0.920 & 0.653 & 0.985 \\
$32.8(\mathrm{OFC})$ & 0.917 & 0.919 & 0.647 & 0.985 \\
63.7 (CC + OFC) & 0.917 & 0.918 & 0.647 & 0.985 \\
0.91 (CC/OFC) & 0.750 & 0.895 & 0.540 & 0.956 \\
\hline
\end{tabular}

$\mathrm{PPV}=$ positive predictive, $\mathrm{NPV}=$ negative predictive value. cut-off points from this study, a colour coded tape can easily identify three weight groups. Those weighing more than $2500 \mathrm{~g}$ will fall within green, $2000-2500 \mathrm{~g}$ will fall the yellow area, while less than 2000 will be red.

\section{Conclusion}

$\mathrm{CC}$ appears to be the best surrogate for detecting LBW infants. It is easy to measure and demonstrated the best correlation of all the parameters. This finding is in keeping with the WHO recommendation and should be encouraged in the rural areas and primary health care centres where weighing scales are likely not to be available or unreliable. Measuring tape is the only tool required and it is readily available, affordable and easily replaceable when damaged.

\section{Abbreviations}

AUC: Area under the curve; CC: Chest circumference; ESUTH: Enugu State University Teaching Hospital; GA: Gestational age; LBW: Low birth weight; MAC: Mid arm circumference; MCSH: Mother of Christ Specialist Hospital; MTC: Maximum thigh circumference; NBSCU: Newborn special care unit; OFC: Occipitofrontal circumference; ROC: Receiver operating characteristic; SD: Standard deviation; SEE: Standard error of the estimate; SPSS: Statistical package for social sciences; TBAs: Traditional birth attendants; UNICEF: Nations Children Fund; UNTH: University of Nigeria Teaching Hospital; WHO: World Health Organisation. 


\section{Competing interests}

The authors declare that they have no competing interests.

\section{Authors' contributions}

IKN conceived the study, participated in its design and coordination, data collection and entry and helped to draft the manuscript. SNI made substantial contribution to the study design and review of the manuscript. EOO participated in drafting of the manuscript and revised it critically for important intellectual content. GNA participated in the study design and helped to draft the manuscript. BOE participated in data analysis and interpretation and contributed to the drafting the manuscript. JMC participated in data analysis and drafting the manuscript and INA participated in the analysis and interpretation of data. NDU participated data analysis and drafting of the manuscript. All authors participated in drafting the manuscript. All authors read and approved the final manuscript.

\section{Acknowledgements}

We wish to acknowledge Prof. Fidelis Njokanma for his invaluable support, Dr. Uchefuna Chuke, and Mr. Ikenna Samuel Uche for their logistical support and all the nurses and midwives in the study centres for their co-operation and support during the data collection.

\section{Author details}

'Enugu state University Teaching Hospital, Park lane, Enugu, Nigeria.

${ }^{2}$ University of Nigeria Teaching Hospital, Enugu, Nigeria.

Received: 10 March 2014 Accepted: 12 October 2014

Published online: 28 October 2014

\section{References}

1. UNICEF. Monitoring the situation of children and women. http://www. childinfo.org/low_birthweight.html.

2. Lissauer T, Fanaroff A: Epidemiology. In Neonatology at a Glance. Edited by Lissauer T, Fanaroff A. Oxford: Blackwell Publishing Ltd; 2006:12-13.

3. UNICF WHO: Low Birth Weight: Country Regional and Global Estimates. New York: UNICEF; 2004.

4. Save the Children: A slender thread: the vulnerable newborn. In State of the world's newborns; 2001.

5. Kramer MS: Determinants of Low Birth Weight: Methodological assessment and meta- analysis. Bull World Health Organ 1987, 65:663-737.

6. WHO: Use of a simple anthropometric measurement to predict birth weight. WHO Collaborative Study of Birth Weight Surrogates. Bull World Health Organ 1993, 71:157-163.

7. Taksande A, Vilhekar KY, Chaturvedi P, Gupta S, Deshmukh P: Predictor of low birth weight babies by anthropometry. J Trop Pediatr 2007, 53:420-423.

8. Demographic and health surveys Nigeria. http://www.who.int/making pregnancy safer/countries/nig.pdf.

9. WHO: Monitoring low birth weight: an evaluation of international estimates and updated estimation procedure. Bull World Health Organ 2005, 83:178-185.

10. Adimora GN: Contribution of low birth weight and very low birth weight infants to perinatal mortality at the University of Nigeria Teaching Hospital, Enugu-Nigeria. J Coll ofMed 2002, 7:124-127.

11. Kuti O, Orji EO, Ogunlola IO: Analysis of perinatal mortality in a Nigerian teaching hospital. J Obstet Gynaecol 2003, 23:512-514.

12. Uthman OA. Effect of low birth weight on infant mortality: Analysis Using WeibullHazard Model. The Int J Epidemio/ http://www.ispub.com/journal/ theinternet-journal-of-epidemiology/volume-6-number-1/effect-of-low-birthweight-on-infant-mortality-analysis-using-weibull-hazard-model.html

13. Lawn JE, Cousens S, Zupan J: 4 million neonatal deaths: When? Where? Why? Lancet 2005, 365:891-900.

14. Darmstadt GL, Bhutta ZA, Cousens S, Adam T, Walker N, de Bernis L: Neonatal Survival Steering Team: Evidence-based, cost effective interventions: how many newborn babies can we save? Lancet 2005, 365:977-988.

15. Bhargava SK, Ramji S, Kumar A, Mohan M, Marwah J, Sachdev HPS: Mid arm and chest circumferences at birth as predictors of low birth weight and neonatal mortality in the community. BMJ 1985, 291:1617-1619.

16. Naik DB, Kulkarni AP, Aswar NR: Birth weight and anthropometry of newborns. Indian J Pediatr 2003, 70:145-146.
17. Mohsen MA, Youssef MM, Zaki ST, El-Shamy MM: Mid-upper arm, chest and head circumference cut-off points and equations for identifying low birth weight in Egypt. Int J Food Nutr Pub Health 2011, 4:31-38.

18. Ezeaka VC, Egri-Okwaji MTC, Renner JK, Grange AO: Anthropometric measurements in the detection of low birth weight infants in Lagos. Niger Postgrad Med J 2003, 10:168-172.

19. Shajari H, Sadeghzadeh H, Tamidy K: Detection of Low birth weight newborns by anthropometric measurements in Iran. Acta Medica Iranica 1996, 34:43-45.

20. Huque F, Hussain AMZ: Detection of low birth weight new born babies by anthropometric measurements in Bangladesh. Indian J Pediatr 1991, 58:223-231.

21. Verma SS, Ghadiok AK, Kishore N, Singh OP: Head and chest circumferences as predictors of low birth weight in Indian babies. J Trop Pediatr 1996, 42:146-150.

22. Bell EF, Oh W: Fluid and electrolyte management. In Neonatology: Pathophysiology and management of the newborn. 5th edition. Edited by Avery BA, Fletcher MA, Macdonald MG. Philadelphia (PA): Lippincott Williams and Wilkins; 1999:345-361.

23. Macdonald PD, Ross SR, Grant L, Young D: Neonatal weight loss in breast and formula fed infants. Arch Dis Child Fetal Neonatal Ed 2003, 88:472-476.

24. Forfar JO: History taking, physical examination and screening. In Textbook of Paediatrics. 3rd edition. Edited by Forfar JO, Arneil GC. Edinburgh: Churchill Livingstone; 1984:26-71.

25. Ballard JL, Khoury JC, Wedig K, Wang L, Eilers-Walsman BL: New Ballard Score, expanded to include extremely premature infants. J Pediatrics 1991, 119:417-423.

26. Oyedeji GA: Socioeconomic and cultural background of hospitalised children in Ilesha. Niger J Paediatr 1985, 12:111-117.

27. UNICEF: Children in an urban world. In State of The World's Children; 2012.

28. Fawcus SR, Mwase R, Bassett MT: Chest circumference as an indicator of LBW in Zimbabwe. J Trop Paed 1993, 39:484-9.

29. Arisoy AE, Sarman G: Chest and mid arm circumferences: Identification of low birth newborns in Turkey. J Trop Paediatr 1995, 41:34-37.

30. Ak P, Kulkani R, Aneja S, Audu I: Anthropometric standards of privileged neonates in Maiduguri, Nigeria. Cent Afr J Med 1988, 34:78-84.

31. Sreermareddy $C T$, Chuni $N$, Patil R, Singh D, Shakya B: Anthropometric surrogates to identify low birth weight Nepalese newborns: a hospitalbased study. BMC Pediatr 2008, 8:16. doi:10.1186/1471-2431-8-16.

32. Swende TZ: Term birth weight and sex ratio of offsprings of a Nigerian obstetric population. Int J Biol Med Res 2011, 2:531-532.

33. WHO: The incidence of low birth weight: a critical review of available information. Wld HIth Stat Q 1980, 33:197-204.

34. WHO: Public health aspects of low birth weight: Expert committee on maternal and child health. Tech Rep Series 1981, 217:3-16.

doi:10.1186/s13052-014-0081-7

Cite this article as: Ndu et al:: Chest and occipito-frontal circumference measurements in the detection of low birth weight among Nigerian newborns of Igbo ethnicity. Italian Journal of Pediatrics 2014 40:81.

\section{Submit your next manuscript to BioMed Central and take full advantage of:}

- Convenient online submission

- Thorough peer review

- No space constraints or color figure charges

- Immediate publication on acceptance

- Inclusion in PubMed, CAS, Scopus and Google Scholar

- Research which is freely available for redistribution 